\title{
Cultural Heritage, Sustainable Development and Inclusive Growth: Global Lessons for the Local Communities Under a Marketing Approach
}

\author{
Călin Vegheș ${ }^{1}$
}

\begin{abstract}
Seen often like something from the past, bearing a certain, not always clear, significance and probably having a particular value, cultural heritage, in its tangible and intangible forms, is far from being considered an asset that local communities may benefit from. Therefore, the contribution of the cultural heritage to the sustainable development of the local communities is less relevant and expresses accurately the extent toward which individuals and institutions understand, value, care for and enjoy this heritage. Widening of the economic and social inequalities in many of the advanced and emerging economies led toward a different model of growth and development addressing and including the entire community aiming not only to improve the economic performance in terms of the gross domestic product, but also the standards of living of its members in terms of income, employment and overall quality of life. Paper presents the results of an exploratory assessment of the connections between the key indicators describing cultural heritage, sustainable development and inclusive growth, under a vision of marketing, in order to identify potential paths local communities may follow by learning the global lessons on how cultural heritage may support the sustainable development in order to ensure their inclusive growth.
\end{abstract}

Keywords: Cultural heritage, sustainable development, inclusive growth, local communities, marketing

\section{Introduction}

For centuries, cultural heritage has represented more a source of inspiration for writers, poets or historians, or rather a curiosity for those who have had the opportunity to come in contact with it. Only in the first half of the 20th century, with the adoption, in 1931, of the Athens Charter for the Restoration of Historic Monuments, concern for the fate of the cultural heritage received an institutional and international dimension, with an almost exclusive attention given to the restoration and preservation of the historical heritage. The Venice Charter for the Conservation and Restoration of Monuments and Sites, issued in 1964, has reconfirmed the concern for the preservation and restoration of the historical heritage but it was the UNESCO Convention Concerning the Protection of the World Cultural and Natural Heritage (1972) that defined comprehensively the cultural heritage as including: monuments - architectural works, works of monumental sculpture and painting, elements or structures of an archaeological nature, inscriptions, cave dwellings and combinations of features, which are of outstanding universal value from the point of view of history, art or science; groups of buildings - groups of separate or connected buildings which, because of their architecture, their homogeneity or their place in the landscape, are of outstanding 
universal value from the point of view of history, art or science; and sites - works of man or the combined works of nature and man, and areas including archaeological sites which are of outstanding universal value from the historical, aesthetic, ethnological or anthropological point of view.

Three decades later, UNESCO has brought to the light and recognized the value and importance of the intangible components of the cultural heritage issuing the Convention for the Safeguarding of the Intangible Cultural Heritage where this part of the cultural heritage, rather ignored until then, has been defined as including the practices, representations, expressions, knowledge, skills - as well as the instruments, objects, artefacts and cultural spaces associated therewith - that communities, groups and, in some cases, individuals recognize as part of their cultural heritage. This heritage, transmitted from generation to generation, constantly recreated by communities and groups in response to their environment, interaction with nature and history, providing a sense of identity and continuity, is manifested in the domains of: (a) oral traditions and expressions, including language as a vehicle of the intangible cultural heritage; (b) performing arts; (c) social practices, rituals and festive events; (d) knowledge and practices concerning nature and the universe; and (e) traditional craftsmanship (UNESCO, 2003).

While UNESCO visions regarding the tangible and intangible cultural heritage inspire strong technical, content-oriented and exhaustive features, the definition given to the cultural heritage by the ICOMOS International Cultural Tourism Committee (2002) focuses more on the experiences its future discoverers and explorers may enjoy: expressions of the ways of living developed by a community and passed on from generation to generation, including customs, practices, places, objects, artistic expression and values. Cultural heritage takes the forms of tangible (places of human habitation, villages, towns and cities, buildings, structures, art works, documents, handicrafts, musical instruments, furniture, clothing and items of personal decoration, religious, ritual and funerary objects, tools, machinery and equipment, and industrial systems) or intangible (all forms of traditional and popular or folk culture, the collective works originating in a given community and based on tradition - oral traditions, customs, languages, music, dance, rituals, festivals, traditional medicine and pharmacopeia, popular sports, food and the culinary arts and all kinds of special skill connected with the material aspects of culture) heritage.

Cultural heritage deserves and needs a cultural tourist, a „,consumer” in marketing terms, that, according to the classification proposed by McKercher (2002), should have the profile of a purposeful cultural tourist (motivated mainly by the desire to learn about the culture and/or heritage and seeking for a deep cultural experience), or at least that of a sightseeing cultural tourist (motivated by the desire to learn about other culture and/or heritage but satisfied with a more entertainment-oriented experience), respectively a serendipitous cultural tourist (ending-up in a deep cultural experience when getting in touch with a cultural/heritage object even being less motivated to learn about that culture/heritage).

As Robinson and Picard (2006) have observed, tourism is foremost a form of economic development which has cultural resources at its foundations and cultural tourism is a form of economic development that although bound to economic realities is nonetheless 
a means by which individuals and societies can obtain meaning and understanding in an intellectual, emotional and spiritual sense by experiencing, learning and enjoying one another's places and pasts. Under a context in which culture increasingly becomes more important, the assessment and employment of the cultural heritage value should consider its various cultural significance (aesthetic, historic, research, social, spiritual or other), the proper understanding of this process leading to an increased respect for the cultural heritage assets, a more holistic and sustainable approach of its regeneration and capitalization, and, as a consequence, to an even a better quality of life (Bakri et al., 2015). Cultural tourist as „consumer” of this heritage should be positioned in the center of the entire effort of capitalizing the cultural heritage passing through the interconnected stages of heritage cycle proposed by Thurley (2005) - understanding, valuing, caring for and, finally, enjoying it.

In spite of the numerous definitions given in the recent years, the one still considered the most relevant is that comprised by the Brundtland Report (1987) according to which sustainable development is development that meets the needs of the present without compromising the ability of future generations to meet their own needs leading to a progressive transformation of economy and society taking into consideration the social equity between generations. This concept is founded on two key elements: the needs of the individuals and/or communities and the process of satisfying them, respectively the limitations imposed on the environment's ability to meet present and future needs.

Attempting to provide a definition of inclusive growth, Ranieri and Almeida Ramos (2013) have assessed comparatively 15 definitions given, between 2003 and 2011, to this concept by different authors and identified fifteen elements describing its content: inequality (mentioned by 11 authors), poverty (9), growth (6), capabilities / empowerment (5), productive employment (3), opportunity (3), social protection (2), gender inequality (1), access to infrastructure (1), participation (1), targeted policies (1), basic social services (1), good governance (1), barriers for investment (1) and benefits of growth (1). This enumeration of inclusive growth related topics suggest, on a hand, the complexity of the concept expressed by the various aspects that can be considered discussing it and, on the other hand, the prevalence of social aspects in defining the concept emphasizing the social dimension of the inclusive growth.

In the context of this research approach, the OECD vision according to which inclusive growth is economic growth distributed fairly across society and creating opportunities for all appears more appropriate. This vision (OECD, 2018) underlines the importance of creating an economic and a business environment attracting new firms and boosting communities, capable to ensure people are able to earn the wages they need to thrive, under a fairer and more effective tax system, as well as of the investments in essential public services employed to build more cohesive societies, taking into consideration the new context characterized by globalization, digitalization, and demographic shifts.

The connection between cultural heritage, cultural tourism, sustainable development and inclusive growth is represented by the way in which cultural heritage, capitalized through and by cultural tourism, represent a determinant for the sustainable development and inclusive growth of the local communities owning and/or managing it and, by aggregation, of the entire economy and society. 


\section{Methodological Notes}

The overall scope of the research was to explore the links between cultural heritage, sustainable development and inclusive growth, leaving from the assumption that cultural heritage can be a resource whose exploitation can support the sustainable development of communities that own or manage it, supplemented by the idea that a complete sustainable development must involve as much as possible the local communities and ensure the largest possible participation of each member in the benefits generated. In this context, the travel and tourism has been considered the most relevant industry, and cultural tourism the most appropriate activity to capitalize the existing cultural heritage in a community or country.

The objectives of exploratory research were to measure and assess the relationships between the cultural heritage and: (1) the travel and tourism industry; (2) sustainable development; and (3) inclusive growth.

The hypotheses associated with the exploratory research objectives assumed that:

(1) there should be a significant association between the cultural heritage and the travel and tourism industry, as tangible and/or intangible heritage elements may represent a purpose of the holidays, as well as a strong motivator for an important part of those visiting different tourist destinations;

(2) there should be a significant association between the cultural heritage and sustainable development, as tangible and/or intangible cultural heritage assets could contribute, through their exploitation, to the sustainable development of local communities and of the country as a whole;

(3) there should be a significant association between the cultural heritage and inclusive growth as, on a hand, members of local communities could be actively involved in preserving, promoting and capitalizing of the existing cultural heritage, and on the other hand, the benefits generated by the capitalization of the cultural heritage could be distributed to the largest possible number of members of the local community who owns and/or manages it.

In order to achieve the research objectives and to verify their associated assumptions, a set of research variables, capable of describing cultural heritage, the travel and tourism industry, sustainable development and inclusive growth, was built. Thus:

- cultural heritage has been defined through the:

o CWHs: number of World Heritage cultural sites in the country (2016), according to the definition given by the World Heritage Committee and inclued in the UNESCO World Heritage List;

O ICH: number of oral and intangible heritage practices and expressions (2016), according to the definition given by the Intergovernmental Committee for the Safeguarding of the Intangible Cultural Heritage and included in the UNESCO World Heritage List;

o CHDD: cultural and entertainment tourism digital demand (2016) expressed by the number of online searches indexed on a scale from 0 to 100 , according to the Country Brand Ranking, Tourism Edition (Bloom Consulting).

- travel and tourism industry has been defined through the: 
O TTCI: travel and tourism competitiveness index (2016) on a scale from 1 to 7 , as determined in the Travel and Tourism Competitiveness Report (2017);

o ITA: international tourist arrivals (2016) according to the United Nations World Tourism Organization (number of arrivals);

O ITIR: international tourist inbound receipts (2016) according to the United Nations World Tourism Organization (expressed in US dollars);

o ARA: average receipt per arrival (2016) according to the United Nations World Tourism Organization (expressed in US dollars).

- sustainable development has been defined through the:

- GDPc: Gross Domestic Product per capita (2016) expressed in constant 2010 dollars, based on the data of the World Bank;

o Emp: Employment-to-population ratio (2016) representing the proportion of a country's population aged 15 and older that is employed, based on the data of the International Labor Organization (ILO) and the World Bank;

o TTGDP: Travel and tourism industry's contribution to the country's Gross Domestic Product (2016) in absolute figures (in US dollars) and as weight in the total of the gross domestic product;

O TTEmp: Travel and tourism industry's contribution to the country's number of work places (2016) in absolute figures (number of jobs) and as a weight in the total number of workplaces.

- inclusive growth has been defined through the:

o IDI: Index of Inclusive Development (2016) on a scale from 1 to 7, as determined in the Inclusive of Development Index Report (2017);

O NIGini: the extent (0 - perfect equality, 100 - perfect inequality) to which the distribution of net income among individuals or households within an economy deviates from a perfectly equal distribution (2016);

o PovRate: poverty rate (2016) defined, for advanced economies, as less than half of the median national income (after taxes and transfers, and adjusted for size of household), and for emerging economies, as the percentage of the population living on less than $\$ 3.20$ a day at 2011 international prices, based on the OECD and World Bank data;

O WeGini: the differences in the distribution of wealth $(0$ - complete equality, 1 complete inequality), based on Credit Suisse Global Wealth Databook (2017);

o PubDebt: public debt, as a share of Gross Domestic Product (2016), consisting of all liabilities that require payment of interest and/or principal by a debtor to a creditor in the future, based on the World Economic Outlook Database.

Secondary data sources considered were the Travel and Tourism Competitiveness Report 2017 (Crotti and Misrahi, 2017), The Inclusive Development Index 2018 (Samans et al., 2018), UNESCO List of World Heritage sites (2018) and the UNWTO Tourism Highlights (2017).

Data on cultural heritage, travel and tourism, sustainable development and inclusive growth indicators were gathered at the level of an investigated group of 44 economies whose main feature was the existence of a number of tangible cultural heritage elements (sites included World Heritage list) higher than the international average (five sites) of 2016. Seen at a glance, the investigated group accounted for more than three quarters in the total number of the World Heritage sites, more than two-thirds in the total number 
of the intangible cultural World Heritage objects, two-thirds in the overall international tourist arrivals and more than two-thirds in the volume of international tourism inbound receipts. Initially selected in the investigated group, Cuba, Ethiopia and Syria have been removed due to the lack of data regarding their travel and tourism competitiveness and inclusive growth. All data regarding the selected economies is presented in table below.

Table 1. Cultural heritage, travel and tourism, sustainable development and inclusive growth data of the 44 selected economies

\begin{tabular}{|c|c|c|c|c|c|c|c|c|c|c|c|c|c|c|c|c|}
\hline E concmies & CWHs & ICH & CHDD & TTCI & ITA & ITIR & ARA & TTGDP & TTEmp & IDI & GDPc & Emp & NIGini & PorRate & WeGini & PubDebt \\
\hline Italy & 47 & 7 & 71 & 5.0 & 50731770 & 39449.2 & 777.6 & 76286.3 & 1118990 & 4.18 & 33705 & 43.1 & 32.7 & 13.3 & 68.7 & 132.7 \\
\hline Spain & 40 & 16 & 83 & 5.4 & 68521255 & 56468.0 & 824.1 & 68843.9 & 937262 & 4.24 & 30588 & 44.4 & 34.1 & 15.9 & 68.00 & 99.3 \\
\hline Gemany & 38 & 2 & 78 & 5.3 & 34971458 & 36867.3 & 1054.2 & 130746.0 & 3010590 & 4.99 & 45270 & 56.9 & 29.5 & 9.1 & 78.9 & 71.0 \\
\hline France & 38 & 15 & 92 & 5.3 & 84451621 & 45920.0 & 543.7 & 89156.5 & 1170310 & 4.83 & 41330 & 50.2 & 26.8 & 8.0 & 72.0 & 96.1 \\
\hline China & 35 & 39 & 82 & 4.7 & 56885700 & 114109.4 & 2005.9 & 224005.0 & 22489600 & 4.40 & 6416 & 68.0 & 50.0 & 11.1 & 81.9 & 42.9 \\
\hline Mexico & 27 & 9 & 50 & 1.5 & 32093323 & 17733.7 & 552.6 & 79673.9 & $376 \$ 030$ & 4.13 & 9517 & 58.6 & 16.1 & 11.0 & 77.9 & 54.0 \\
\hline India & 27 & 13 & 51 & 4.2 & 8027133 & 21012.7 & 2617.7 & 41582.4 & $2345+400$ & 3.38 & 1806 & 52.2 & 47.9 & 58.0 & 87.6 & 69.1 \\
\hline United Kingdor: & 25 & 0 & 79 & 5.2 & 34435840 & 45463.6 & 1320.2 & 103740.0 & 1791220 & 4.69 & 40933 & 58.2 & 32.7 & 10.4 & 73.2 & 89.0 \\
\hline Iran & 20 & 12 & 13 & 3.4 & 5237000 & 3483.0 & 665.1 & 10145.7 & $476) 19$ & 4.29 & 5937 & 39.6 & 36.0 & 0.7 & 77.9 & 15.9 \\
\hline Greece & 16 & 4 & 23 & 4.5 & 23599455 & 15672.7 & 664.1 & 14704.1 & 400983 & 3.68 & 22648 & 39.1 & 33.7 & 15.1 & 67.0 & 176.9 \\
\hline Japan & 16 & 21 & 79 & 5.3 & 19737409 & $249 \$ 2.6$ & 1265.8 & 106659.0 & 1222550 & 4.36 & 44657 & 56.9 & 30.8 & 16.1 & 63.1 & 248.0 \\
\hline Russa & 16 & 0 & 22 & 4.2 & 31346486 & 8465.0 & $2 / 0.0$ & $1 / 839.8$ & y/3)03 & 4.42 & 11039 & 60.2 & 32.8 & 0.2 & 92.3 & 16.4 \\
\hline Portugal & 14 & 6 & 28 & 4.7 & 10140199 & 12705.0 & 1252.9 & 12562.7 & 362797 & 3.94 & 21961 & 51.7 & 33.2 & 13.6 & 71.3 & 129.0 \\
\hline Tursey & 14 & 15 & 28 & 4.1 & 39478000 & 26616.0 & 674.2 & 35897.8 & 599370 & 4.30 & 11525 & 44.8 & 36.4 & 2.6 & 83.2 & 32.9 \\
\hline Poland & 13 & 0 & 14 & 4.1 & 16728000 & 9728.0 & 581.5 & 7999.1 & 275365 & 4.57 & 14581 & 51.3 & 31.6 & 0.3 & 73.0 & 51.3 \\
\hline Sweden & 13 & 0 & 14 & 4.6 & 10522000 & 11322.1 & 1076.0 & 12147.0 & 179767 & 5.30 & 54989 & 58.9 & 25.5 & 8.8 & 83.2 & 43.4 \\
\hline Brazil & 13 & 8 & 66 & 4.5 & 6305838 & 5844.0 & 926.8 & 56316.8 & 2624670 & 4.13 & 11159 & 65.0 & 46.0 & 7.6 & 82.9 & 73.7 \\
\hline Czech Republic & 12 & 5 & 6 & 4.2 & 11143000 & 6048.3 & 542.5 & 4612.3 & 208331 & 4.78 & 20956 & 55.9 & 24.5 & 6.0 & 76.0 & 40.3 \\
\hline Belgium & 12 & 13 & 44 & 4.5 & 8354753 & 11968.2 & 1432.5 & 11157.1 & 119435 & 4.89 & 44863 & 48.8 & 24.4 & 10.0 & 64.1 & 106.1 \\
\hline Korea, Rep. & 11 & 21 & 17 & 4.6 & 13231651 & 15214.3 & 1149.8 & 24187.6 & 561196 & 4.95 & 25023 & 58.8 & 29.8 & 14.4 & 71.9 & 37.9 \\
\hline United States & 10 & 0 & 31 & 5.1 & 77510282 & 201523.0 & 2638.7 & 187967.0 & 5633170 & 1.11 & 51186 & 58.5 & 37.0 & 17.5 & 86.2 & 105.2 \\
\hline Israel & 9 & 0 & 23 & 3.8 & 2799502 & 5364.5 & 1916.2 & 5897.8 & 85707 & 4.28 & 32828 & 59.1 & 36.6 & 18.6 & 77.2 & 64.1 \\
\hline Mosocco & 9 & 6 & 16 & 3.8 & 10176762 & 5852.8 & 575.1 & 7735.4 & 731525 & 3.89 & 3238 & 45.5 & 39.6 & 15.5 & 79.0 & 64.1 \\
\hline Austria & 9 & 4 & 16 & 4.9 & 26718945 & 18218.0 & 681.8 & 20438.0 & 261100 & 5.05 & 47668 & 57.9 & 28.8 & 9.0 & 78.5 & 86.2 \\
\hline Netherlants & 9 & 0 & 18 & 4.6 & 15007000 & 13210.9 & 880.3 & 13861.0 & 434333 & 5.28 & 30925 & 59.7 & 25.3 & 8.4 & 74.3 & 65.1 \\
\hline Switzerland & 9 & 1 & 24 & 4.9 & 9304633 & 16361.1 & 1758.4 & 13844.2 & 141798 & 5.75 & 75551 & 65.0 & 29.7 & 8.6 & 72.1 & 45.7 \\
\hline Peru & 8 & 10 & 26 & 4.0 & $3435 / 09$ & 3319.1 & 960.1 & $13 / 2.6$ & 390500 & 4.41 & $29 / 4$ & 73.1 & 45.1 & 9.0 & 80.1 & 24.0 \\
\hline Carada & 8 & 0 & 29 & 5.0 & 17977285 & 16557.8 & 921.0 & 28498.4 & 657500 & 4.90 & 50001 & 61.5 & 31.4 & 12.6 & 73.2 & 91.5 \\
\hline Hungary & 7 & 5 & 9 & 4.1 & 14316000 & 5343.6 & 373.3 & 4778.6 & 246232 & 4.57 & 14375 & 47.9 & 29.3 & 0.5 & 62.5 & 75.3 \\
\hline Norway & 7 & 1 & 11 & 4.6 & 5361000 & 4951.8 & 923.7 & 12514.9 & 144658 & 6.02 & 89741 & 62.6 & 22.9 & 7.8 & 79.8 & 27.9 \\
\hline Turisia & 7 & 0 & 6 & 3.5 & 5359309 & 1380.8 & 257.7 & 2524.5 & 185290 & 3.94 & 4235 & 41.3 & 36.7 & 8.4 & 73.1 & 55.7 \\
\hline Croatia & 7 & 15 & 18 & 4.4 & 12683179 & 8833.3 & 696.5 & 4932.7 & 130523 & 4.28 & 13807 & 42.7 & 30.7 & 2.2 & 64.5 & 86.7 \\
\hline Bulgaria & 7 & 5 & 7 & 4.1 & 7099000 & 3146.2 & 443.2 & 1617.0 & 92413 & 4.37 & 7502 & 47.2 & 33.7 & 4.7 & 65.8 & 26.3 \\
\hline Chile & 6 & 2 & 27 & 4.1 & 4478336 & 2408.5 & 537.8 & 8043.7 & 269317 & 4.46 & 14626 & 58.0 & 47.1 & 2.1 & 80.5 & 17.5 \\
\hline Pakistan & 6 & 3 & 11 & 2.9 & 965498 & 317.0 & 328.3 & 7362.0 & 1429580 & 3.56 & 1152 & 51.7 & 37.6 & 36.9 & 72.7 & 63.6 \\
\hline Algeria & 6 & 6 & 1 & 3.1 & 1710000 & 307.7 & 179.9 & 5887.4 & 327306 & $\mathrm{na}$ & 1791 & 10 & 31.2 & $\mathrm{na}$ & 71.7 & 9.1 \\
\hline Bolivia & 6 & 5 & 8 & 3.3 & 882000 & 692.6 & 785.3 & 1012.3 & 116771 & 4.02 & 2373 & 70.6 & 44.5 & 12.7 & 77.9 & 36.2 \\
\hline Egypt & 6 & 2 & 67 & 3.6 & 9139104 & 6065.1 & 663.6 & 14482.8 & 1110550 & 2.94 & 2707 & 42.8 & 46.4 & nas & 81.1 & 89.0 \\
\hline Finland & 6 & 0 & 9 & 4.4 & 2622039 & 2559.4 & 976.1 & 4735.3 & 53321 & 5.04 & 45289 & 54.3 & 25.0 & 6.8 & 76.6 & 62.5 \\
\hline Ukraine & 6 & 2 & 12 & 3.3 & 12428286 & 1082.0 & 87.1 & 1304.8 & 214364 & 3.67 & 2824 & 53.0 & 25.5 & 0.1 & 91.7 & 80.1 \\
\hline Colombia & 6 & 9 & 16 & 3.8 & 2978180 & 4245.3 & 1425.5 & 5880.3 & 556135 & 4.08 & 7448 & 60.7 & 48.5 & 13.2 & 76.2 & 50.6 \\
\hline Konama & 0 & 0 & 1 & 3.8 & 2234220 & $1 / 12.0$ & 706.1 & 2318.9 & $189 / 69$ & 4.23 & 9321 & 22.8 & 32.1 & 4.1 & 13.0 & 39.3 \\
\hline Sri Lanka & 6 & 0 & 11 & 3.8 & 1798380 & 2980.7 & 1657.4 & 3546.9 & 344352 & 4.01 & 3638 & 52.4 & 37.1 & 14.6 & 80.7 & 76.0 \\
\hline Argentina & 6 & 2 & 51 & 4.1 & 5736384 & 4400.2 & 767.1 & 22152.2 & 671769 & 4.43 & 10515 & 55.9 & 38.9 & 4.3 & 78.7 & 52.1 \\
\hline
\end{tabular}

Data sources: Crotti and Misrabi, 2017, Samans et al., 2018, UNESCO (2018) and UNWTO (2017).

Correlation coefficients were computed to measure the existing associations between cultural heritage, travel and tourism, sustainable development and inclusive growth, with the intensity, nature and significance of associations being interpreted as a scale between 0 (non-existent association) and 1 (perfect association).

\section{Main Findings}

Cultural heritage contributes in a differentiated extent to the overall competitiveness of the travel and tourism industry: tangible cultural heritage is more significantly associated $(r=0.5747)$ with a higher competitiveness of the industry while intangible cultural heritage is less significantly related $(r=0.2068)$. Digital demand for 
tourism and cultural entertainment is significantly and positively associated $(r=0.6260)$ with the overall competitiveness of the travel and tourism industry at the level of the investigated group. The existence of a valuable cultural heritage, either tangible or intangible, has a favorable impact on a tourist destination increasing its attractiveness and the interest of the tourists in discovering, exploring and enjoying its cultural heritage. The most competitive travel and tourism is specific for the destinations most sought by the tourists, particularly online, and that have a cultural heritage whose value has been certified by international entities (such as UNESCO) and recognized through the consistent tourist flows attracted to every year.

The cultural heritage determines a positive evolution of the flow of international tourists: the number of international arrivals tends to increase significantly in the destinations with a valuable tangible cultural heritage $(r=0.7223)$, and relatively significantly in those having a valuable intangible cultural heritage $(\mathrm{r}=0.3399)$. The arrival of international tourists is significantly associated with the digital demand for cultural and entertainment tourism $(r=0.6379)$ supporting the ideas that cultural heritage is an important reference in choosing a holiday destination, and the behavior of tourists has a strong cultural determination: they get information about the cultural heritage in the potential holiday destinations and choose those that offer more exciting opportunities to discover and enjoy the tangible and/or intangible cultural heritage.

The association between the cultural heritage and the receipts generated by international tourism is less intense but still positive. Tangible heritage appears to be better associated $(\mathrm{r}=0.3979)$ than intangible one $(\mathrm{r}=0.2750)$ with the value of international tourism receipts for at least two reasons: on the one hand, the receipts generated by the tangible cultural heritage are easier to identify and measure over time (for instance, visiting a memorial house involves buying an entry ticket whose tariff is clearly specified, the total number of entries is monitored, the amount of revenue generated by the sale of entry tickets can be easily determined) while the receipts generated by intangible cultural heritage are slightly more difficult to trace and quantify, or sometimes they even cannot be measured (for instance, a custom can be experienced at a festival where access is free or following an event that naturally occurs within a families or at the level of a local community). These results indicate that cultural heritage has the ability to generate, directly or indirectly, more or less clearly quantifiable, an income that can be used by those who manage or benefit from its capitalization through cultural tourism. The significant association between digital demand for tourism and cultural entertainment and the receipts from cultural tourism $(\mathrm{r}=0.4281)$ indicates a certain consistency in the behavior of the cultural tourist who seeks information about a destination rich in cultural heritage, actually visits it and, very important, has the willingness to spend for products and/or services associated with the cultural heritage with which it came into contact.

Similarly, the association between the cultural heritage and the average value of the receipt per arrival is relatively poor, but positive. The intangible heritage $(r=0.2147)$ seems to impact more significantly than the tangible one $(r=0.1617)$ to the average revenue per arrival and the digital demand for tourism and cultural entertainment contributes slightly better in this respect $(r=0.2764)$. These results, as well as those presented above, support the idea that intangible cultural heritage should receive a greater attention from the part of the local communities and society in general. Even 
UNESCO has later recognized its importance: if the tangible cultural heritage has got an international recognition in 1972 and the List of World Heritage Sites has been opened in 1978 by the inclusion of cultural heritage objectives from Canada, Ecuador, Ethiopia, Germany, Poland, Senegal and the United States, the intangible cultural heritage has obtained the similar recognition only in 2003 and the List of Intangible Cultural Heritage opened in 2008 .

Sustainable development is a concept rather difficult to define and measure: on the one hand because it requires consideration of very diverse and complex aspects demographic, economic, cultural, technological, political or environmental - and selection of those that express in the best way or are the most representative to describe it and explain it; on the other hand, because once the representative aspects defined, it is difficult to identify the appropriate indicators to quantify and allow each aspect to be measured.

Under this research approach, sustainable development can be associated with the ability of an economy to deliver those goods and services that are needed to satisfy the needs of consumers, while also providing them with opportunities to earn incomes that will allow them to live a decent life. The Gross Domestic Product per capita can be seen, in this context, as an indicator relevant enough to express the ability of an economy to deliver goods and services, while the number of workplaces is a very plastic expression of the opportunities that consumers have them to earn the income supporting their purchasing power. In order to connect better the cultural heritage and sustainable development through the travel and tourism, indicators on the contribution of this industry to the Gross Domestic Product (in absolute terms and as a share of the total) and on the creation of workplaces (also in absolute value and share of the total) have been considered.

The cultural heritage, in both tangible and intangible forms, seems to contribute to a very low extent to the formation of the Gross Domestic Product: correlation coefficients $(r=0.1200$, respectively $r=-0.1998)$ indicate a low or even very low association between the cultural heritage and gross domestic product per capita. Similarly, both tangible and intangible cultural heritage appears to contribute very modestly to the creation of workplaces at the overall level of the investigated economies. The values of correlation coefficients $(r=-0.1117$, respectively $r=0.0169)$ indicate a very low association between the cultural heritage and the employment rate of the active population (at least 15 years old) at the level of the investigated economies. The results are not surprising given that, on the one hand, the cultural heritage considered under this research approach, undoubtedly extremely valuable - being included in the World Heritage list - represents only a small part of the entire tangible or intangible cultural heritage of the investigated economies group and, on the other hand, the contribution of the industries (primarily the travel and tourism) whose operation is based on its capitalization to the formation of gross domestic product is also relatively modest.

Focusing the analysis on the macroeconomic performances of the travel and tourism industry highlights the much more significant role that cultural heritage plays in both the formation of gross domestic product generated by industry and the workplaces created within it. Association between the cultural heritage and the gross domestic product generated by the travel and tourism industry appears to be relatively important $(r=0.3610$, in the case of tangible, respectively $r=0.2186$, in the case of the intangible 
cultural heritage), while the association between the cultural heritage and workplaces created within the industry appear to be even more important $(\mathrm{r}=0.4118$, in the case of tangible, respectively $\mathrm{r}=0.5281$, in the case of the intangible cultural heritage). An improved restoration, preservation, promotion and capitalization of the existing cultural heritage within a tourist destination can generate a significant impact in terms of the sustainable development of the local community owning or managing it, as well as of the entire economy, under the forms of a higher gross domestic product generated by the travel and tourism industry and a growing number of employment opportunities, within the industry or in related industries.

Turning back to the impact on sustainable economic development, its assessment should take into account that the gross domestic product generated by the main industry capitalizing on cultural heritage holds, at the level of the investigated group of economies, an average share of $3.6 \%$ (with highest weights, of $10.1 \%$ in Croatia, $7.7 \%$ in Morocco, $7.6 \%$ in Greece or $7.0 \%$ in Mexico, respectively the lowest, of $1.3 \%$ in Romania, $1.4 \%$ in Ukraine and $1.5 \%$ in Russian Federation), while workplaces in the industry account for an average share of $4.1 \%$ in the total of employment (with highest weights, of $11.3 \%$ in Greece, $9.8 \%$ in Croatia, $7.9 \%$ in Portugal, $7.5 \%$ in Mexico, 1.2 $\%$ in Ukraine, respectively the lowest, of $1.4 \%$ in Russian Federation and $1.7 \%$ in Poland). A greater impact in terms of gross domestic product and workplaces created in the industry could be expected as a consequence of expanding the assembly of tangible and intangible cultural heritage recognized for its outstanding universal value and of increasing the intensity of preservation, restoration, promotion and capitalization of this heritage. A richer, more diverse, better preserved and properly promoted heritage would increase the attractiveness of a tourist destination - whether it is a local community or the entire economy - leading to an increased number of international tourists and therefore to additional revenues generated by the travel and tourism industry, most likely accompanied by an increase in the industry's workplaces.

Measuring the association between cultural heritage and inclusive growth has raised a conceptual and operational problem: on the one hand, about conceptualizing a relationship which, quite possible on a theoretical perspective, is a rather desirable in the real terms; on the other hand, about finding appropriate indicators not only to express inclusive growth, but also to allow the measurement of association to cultural heritage. In a broad sense, the relationship between the cultural heritage, whether tangible or intangible, and the inclusive growth (expressed by index of inclusive growth) is very poor $(\mathrm{r}=-0.0140$, respectively $\mathrm{r}=-0.1062)$. In addition, the negative direction of this association suggests that a richer and/or an enhanced cultural heritage would facilitate a less inclusive growth of local communities or entire economy, which would not surprise so much if the things were viewed from a macro perspective: local communities (as well as countries) that would better capitalize their cultural heritage could obtain comparatively better outputs (including higher incomes).

The association between cultural heritage and the distribution of net income among individuals or households is poor $(r=0.2649$, for intangible cultural heritage $)$ or quite very poor ( $\mathrm{r}=0.0429$, for tangible cultural heritage). Capitalization of the cultural heritage is expected to generate first the sustainable development of the local communities, consequently of the entire economy and only after that a more balanced distribution of 
net income among their members. If the capitalization is made using mostly local resources and involving, in different forms, an increasingly larger number of community members, the revenues obtained will be later redistributed so that as many individuals or households will benefit.

The association between cultural heritage and the poverty rate of the investigated economies is rather poor $(r=0.1898$, in the case of tangible, respectively $r=0.1305$, in the case of intangible cultural heritage). A more effective capitalization of the cultural heritage generates an increased income, which could mean a reduction in the poverty rate at the level of the local communities and, consequently, of the entire economy. Given the geographical distribution of cultural heritage, differences in terms of value and, last but not least, the local community's capability to capitalize it, the impact on the poverty rate, albeit beneficial, cannot eradicate, but could diminish the poverty.

The association between cultural heritage and distribution of wealth is poor and even very poor and of and negative direction $(r=-0.0598$, in the case of tangible, respectively $r=-0.1750$, in the case of intangible cultural heritage). The cultural heritage does not currently have a significant impact on the way wealth is distributed within the economies, implicitly within the local communities. A wider cultural heritage or a more extensive employment of this heritage would impact wealth distribution favoring the communities that have either a richer heritage or better capabilities to capitalize on it.

Last but not least, the association between the cultural heritage and the public debt is relatively poor or even very poor $(r=0.2628$, in the case of tangible, respectively $\mathrm{r}=0.1389$, in the case of intangible cultural heritage). Restoring, preserving, promoting and capitalizing on cultural heritage involves the attraction and employment of sometimes considerable financial resources. Even from an individual perspective, discovering, exploring and experiencing the cultural heritage may involve a significant financial effort. As from the communities' perspective, restoration and preservation of the cultural heritage may demand high amount of money. Both individuals and communities may not have the financial resources at their disposal and need to borrow them which may lead to an increase in public debt.

\section{Conclusions and Limits of the Research}

Analysis of the associations between the cultural heritage, travel and tourism industry, sustainable development and inclusive growth at the level of group of 44 selected economies, allows drawing the following conclusions:

- cultural heritage is an important resource for the travel and tourism industry and cultural tourism is the most appropriate way to capitalize on tangible or intangible heritage. Revitalization of the cultural heritage, accompanied by an effective promotion will allow local communities to transform in attractive tourist destinations, providing opportunities for the travel and tourism industry to develop cultural tourism products and/or services and giving cultural tourists chances to discover, explore and enjoy cultural experiences;

- contributing to the macroeconomic performances of the travel and tourism industry gross domestic product generated and workplaces created, cultural heritage supports the sustainable development of the industry. Its contribution to the overall sustainable 
development depends, however, on the share of the travel and tourism industry in the overall market and on the capacity of other industries or markets to consider cultural heritage as a relevant resource and to capitalize on it;

- currently, the contribution of cultural heritage to the inclusive growth is very limited. Its improvement depends on building a mechanism by which local resources - raw materials, technologies, know-how and creativity - can be used by the local economy to produce goods and services used to manage, promote and capitalize on the existing cultural heritage, and the results to be redistributed among its members.

These conclusions must be considered under the limits of this research approach. First concerns the content of cultural heritage, which in this case included only the tangible and intangible heritage inscribed in the UNESCO World Heritage lists. Both the group of 44 selected economies and the other economies of the World dispose of a heritage that even without enjoying the recognition brought by the inclusion on UNESCO lists, is at least comparable in terms of the content and/or interest of the public. As on the one hand, the current research aimed only to explore the connections between the cultural heritage and travel and tourism industry, sustainable development and inclusive growth, and, on the other hand, data regarding the tangible or intangible cultural heritage are scarcely available, the limitation to the 44 selected economies did not affect providing answers to the research questions and reaching of the overall scope of the research.

Second refers to the indicators used to describe and measure sustainable development and inclusive growth under this research approach. Undoubtedly, the employed indicators are appropriate to describe and characterize both concepts, but in connection with those regarding the cultural heritage produce results that need to be considered with caution. Still, given the overall scope of the research and its nature, they can be used as exploratory measures of the investigated topics. A more in-depth research of the associations between the cultural heritage, sustainable development and inclusive growth requires finding indicators that can better capture how cultural heritage supports the sustainable development and inclusive growth of the local communities.

Finally, a third limit of the current research - that may be transformed in a future direction of research - is the level of conducting the measurement, represented, in this case, by the economy of the selected countries. Although both sustainable development and the inclusive growth tend to be defined, measured, assessed and tackled at the level of the overall economy, a more appropriate approach should be implemented focusing the evaluation on the local communities and individuals due to their particular positions of owners and/or managers, in fact providers, respectively, of ,consumers" of the cultural heritage, and, nonetheless, their common roles of participants in the sustainable development initiatives and, also, to the inclusive growth through the redistribution of the results. Local communities, by their members, should be actively involved in the restoration, preservation, promotion and capitalization of the local tangible and/or intangible cultural heritage aiming to grow in a sustainable and inclusive manner.

\section{References}

Bakri, A. F., Ibrahim, N., Ahmad, S. S., Zaman, N. Q. (2015). Valuing Built Cultural Heritage in a Malaysian Urban Context. Procedia-Social and Behavioral Sciences 170, 381-389. 
Crotti, R., Misrahi, T. (2017). Travel and Tourism Competitiveness Report 2017: Paving the way for a more sustainable and inclusive future. Retrieved from http://www3.weforum.org/docs /WEF_TTCR_2017_web_0401.pdf.

ICOMOS International Cultural Tourism Charter (2002). Principles And Guidelines For Managing Tourism At Places Of Cultural And Heritage Significance, International Council on Monuments and Sites, ICOMOS International Cultural Tourism Committee. Retrived from http://www.icomos.no/wpcontent/uploads/2014/04/ICTC-Charter.pdf.

McKercher, B. (2002). Towards a Classification of Cultural Tourists, International Journal of Tourist Research 4, 29-38.

OECD (2018). Opportunities for All: The Framework for Policy Action on Inclusive Growth. Retrieved from https://oe.cd/2hJ.

Ranieri, R., Almeida Ramos, R. (2013). Inclusive growth: Building up a concept. Retrieved from http://www.ipc-undp.org/pub/IPCWorkingPaper104.pdf.

Robinson, M., Picard, D. (2006). Tourism, Culture and Sustainable Development. Retrieved from http://unesdoc.unesco.org/images/0014/001475/147578e.pdf.

Samans, R., Drzeniek-Hanouz, M., Corrigan, G., Burke, M. (2018). The Inclusive Development Index 2018. Retrieved from http://reports.weforum.org/the-inclusive-development-index-2018/.

Thurley, S. (2005). Into the future. Our strategy for 2005-2010. Conservation Bulletin 49, 26-27.

UNESCO (1972). Convention Concerning the Protection of the World Cultural and Natural Heritage.Retrieved from http://whc.unesco.org/?cid=175.

UNESCO (2003). Convention for the Safeguarding of the Intangible Cultural Heritage. Retrieved from https://ich.unesco.org/en/convention\#art2.

UNESCO (2018). World Heritage List. Retrieved from http://whc.unesco.org/en/list/.

United Nations (1987). Report of the World Commission on Environment and Development: Our Common Future. Retrieved from http://www.un-documents.net/our-common-future.pdf.

United Nations World Tourism Organization (2017). UNWTO Tourism Highlights: 2017 Edition. Retrieved from https://www.e-unwto.org/doi/pdf/10.18111/9789284419029. 